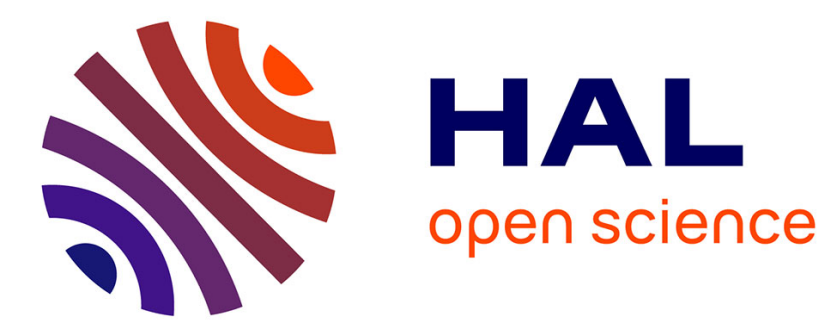

\title{
Synthesis of a Bolm's 2,2'-Bipyridine Ligand Analogue and Its Applications
}

Eva Bednářová, Martin Dračínský, Štefan Malatinec, Ivana Císařová, Frédéric

Lamaty, Martin Kotora

\section{- To cite this version:}

Eva Bednářová, Martin Dračínský, Štefan Malatinec, Ivana Císařová, Frédéric Lamaty, et al.. Synthesis of a Bolm's 2,2'-Bipyridine Ligand Analogue and Its Applications. Advanced Synthesis and Catalysis, 2018, 360 (15), pp.2869-2878. 10.1002/adsc.201800452 . hal-02370736

\section{HAL Id: hal-02370736 \\ https://hal.science/hal-02370736}

Submitted on 17 Dec 2020

HAL is a multi-disciplinary open access archive for the deposit and dissemination of scientific research documents, whether they are published or not. The documents may come from teaching and research institutions in France or abroad, or from public or private research centers.
L'archive ouverte pluridisciplinaire $\mathbf{H A L}$, est destinée au dépôt et à la diffusion de documents scientifiques de niveau recherche, publiés ou non, émanant des établissements d'enseignement et de recherche français ou étrangers, des laboratoires publics ou privés. 


\title{
Synthesis of a Bolm's 2,2'-Bipyridine Ligand Analogue and Its Applications
}

\author{
Eva Bednářová, ${ }^{\mathrm{a}, \mathrm{d}}$ Martin Dračínský, ${ }^{\mathrm{b}}$ Štefan Malatinec, ${ }^{\mathrm{a}}$ Ivana Císařová, ${ }^{\mathrm{c}}$ \\ Frédéric Lamaty, ${ }^{\mathrm{d}, *}$ and Martin Kotora ${ }^{\mathrm{a}, *}$
}

a Department of Organic Chemistry, Faculty of Science, Charles University, Hlavova 8, 12843 Praha 2, Czech Republic $+420221951058$

$+420221951326$

E-mail: martin.kotora@natur.cuni.cz

b Institute of Organic Chemistry and Biochemistry, Academy of Sciences, Flemingovo náměstí 2, 16610, Praha, Czech Republic

c Department of Inorganic Chemistry, Faculty of Science, Charles University, Hlavova 8, 12843 Praha 2, Czech Republic

d Institut des Biomolécules Max Mousseron IBMM), UMR 5247, CNRS, Université de Montpellier, ENSCM, Campus Triolet, Place Eugène Bataillon, 34095 Montpellier cedex 5, France

+33 (0) 467143847

+33 (0) 467144866

E-mail: frederic.lamaty@umontpellier.fr

\begin{abstract}
A new method of synthesis of an analogue of Bolm's 2,2'-bipyridine ligand based on the catalytic $[2+2+2]$ cyclotrimerization of 1-halodiynes with nitriles was developed. Crucial step of the whole synthesis turned out to be homodimerization of a substituted 2-bromopyridine to the corresponding bipyridine, that was studied and optimized. The newly prepared bipyridine $(S, S)-\mathbf{2}$ was then tested as a chiral ligand in metalcatalyzed enantioselective reactions. Out of the studied reactions the most promising results were obtained in epoxide ring opening ( $82 \%$ yield, $98 \%$ ee) and Mukaiyama aldol reaction ( $>96 \%$ yield, $99 / 1 \mathrm{dr}, 92 \%$ ee). In the case of Mukaiyama-aldol reaction as well as in the Michael addition, novel ligand $\mathbf{2}$ proved its robustness compared to Bolm's ligand as it was less sensitive to the purity of used reagents.
\end{abstract}

Keywords: catalysis; enantioselective synthesis; cyclotrimerization; bipyridines; chiral ligands

\section{Introduction}

$2,2^{\prime}$-Bipyridines and their derivatives form an important class of heteroaromatic compounds with application in various fields of chemistry such as supramolecular and macromolecular chemistry, photochemistry and electrochemistry but more significantly, thanks to their unique coordination abilities, as ligands able to complex almost all imaginable metals. ${ }^{[1]}$ On the contrary to regularly used phosphine or cyclopentadienyl ligands, bipyridine ligands are generally more stable both to moisture and oxidation (air), which is simplifying their synthesis, handling, and storage. In this manner bipyridines have found numerous applications in transition metal-catalyzed racemic and enantioselective reactions. For example, chiral 2,2'-bipyridine ligands have found applications in metal-catalyzed asymmetric reactions such as cyclopropanation of olefins, alkylation and allylation of aldehydes, hydrosilylation of ketones, allylic oxidation of cycloalkenes. ${ }^{[2]}$ It is also worth mentioning that the bipyridine scaffold can be found in several natural compounds such as caerulomycins,${ }^{[3]}$ orellanine,${ }^{[4]}$ lavendamycin ${ }^{[5]}( \pm)$-streptonigrin, ${ }^{[6]}$ and $(+)$-complanadine $^{[7]}$ (Figure 1).

One of the most comprehensively studied member of this class of compounds is diol 1 possessing the 2,2'bipyridine scaffold (Bolm's ligand) with $(R, R)$ configuration (Figure 2) that was designed and synthesized by Bolm et al. in $1990 .^{[8]}$ The synthetic approach was slightly modified by Kobayashi et al. in 2005, who prepared $(S, S)-\mathbf{1} .^{[9]}$ Bolm's ligand $\mathbf{1}$ proved to be a useful chiral ligand in various types of metal-catalyzed asymmetric reactions as e. g. allylation of aldehydes, ${ }^{[10]}$ opening of epoxides, ${ }^{[11,12,13]}$ Michael addition, ${ }^{[14]} \mathrm{Mu}-$ kaiyama-aldol reaction, ${ }^{[15]}$ hydroxymethylation, ${ }^{[16]}$ $\mathrm{C}-\mathrm{H}$ activation of indols, ${ }^{[17]}$ and most recently DielsAlder reaction. ${ }^{[18]}$ In addition, its complexes with non- 


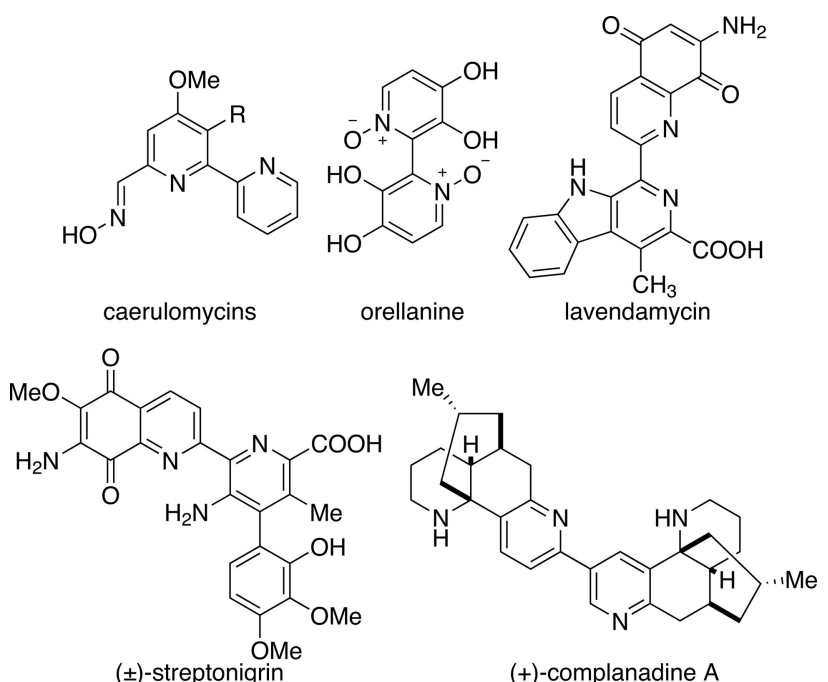

Figure 1. Natural compounds possessing the 2,2'-bipyridine scaffold.

toxic metal salts (e.g. $\mathrm{Fe}, \mathrm{Bi}, \mathrm{Sc}$ ) also showed interesting behavior in the aqueous media making it an important player in the field of green chemistry. ${ }^{[16,19,20]}$

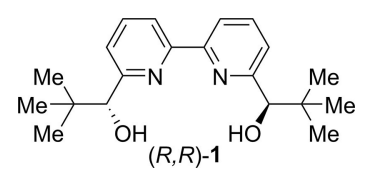

Figure 2. Bolm's 2,2'-bipyridine ligand $(R, R)$.

Despite the abovementioned interesting results, studies of the dependence of the activity of the ligand on changes in its structure have been almost exclusively limited to the variations of the $t$-Bu part of the alcohol moiety in $\mathbf{1}$ to some other groups (Me, $i-\mathrm{Pr}$, $\mathrm{Ph}$, Napth etc.). ${ }^{[9,11]}$ Only one example of a derivative with substituents in $3,3^{\prime}$ position $(\mathrm{Me})$, was efficiently applied in alcoholysis and aminolysis of meso-epoxides. $^{[11,21]}$

\section{Results and Discussion}

Ligand design considerations. From the point of view ligand design, further elaboration of the basic skeleton of Bolm's ligand is desirable, because it could lead to development of new ligands capable of producing even higher asymmetric induction. One option is to add additional rings onto the pyridine scaffold that would restrict rotation along the $\mathrm{C}-\mathrm{C}$ bond connecting the pyridine rings as in the modified Bolm's ligand 2 (Figure 3). This could potentially induce a conformationally dynamic chirality. ${ }^{[22]}$ If the pyridine rings cannot lie in one plane, resulting conformational rigidity of the transition state will be higher. This has been already demonstrated in the case of $\mathrm{Co}^{[23]}$ or $\mathrm{Re}^{[24]}$ complexes, and may serve as typical examples. In addition, it is reasonable to expect that the presence of an alkyl group in the 3 and $3^{\prime}$ as well as 4 and $4^{\prime}$ positions would increase, through its inductive effect, electron density on the nitrogen atom ${ }^{[25,26]}$ and thus enhance the coordination to a transition metal. In this respect it has been noticed that the presence of alkyl group in the positions 3 and $3^{\prime}$ and as well as 4 and $4^{\prime}$ of the bipyridine ligand had a positive effect on the performance of Cr-bipyridine catalytic system. ${ }^{[27]}$

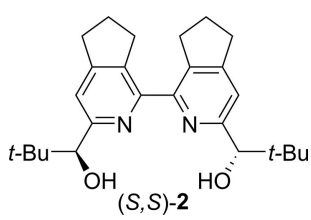

Figure 3. Bolm's ligand analog 2.

Our intended approach to the modified Bolm's ligand was based on the following retrosynthetic analysis (Scheme 1): a) catalytic homocoupling of a bicyclic 2-halopyridine that in turn could be prepared by b) catalytic cyclotrimerization of 1-halohepta-1,6diyne with electron-poor nitriles. We have recently developed a new type of Ru-complex catalyzed $[2+$ $2+2$ ] cyclotrimerization of halodiynes with electronpoor nitriles, ${ }^{[28]}$ which would support this approach.

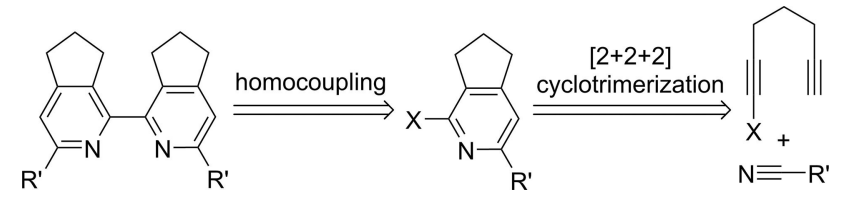

Scheme 1. Retrosynthetic analysis of an approach to a modified Bolm's ligand.

Synthesis of ligand 2. Starting hepta-1,6-diyne 3 was deprotonated with LiHMDS followed by reaction with trimethylsilyl chloride to furnish the monosilylated diyne 4. Its subsequent deprotonation with $n$ $\mathrm{BuLi}$ and reaction with NBS provided diyne 5 in $52 \%$ isolated yield after two steps (Scheme 2). It should be noted that the standard conditions for the synthesis of bromoalkynes by using $\mathrm{AgNO}_{3}$, NBS could not be applied, because of the unwanted removal of the TMS-group during the course of the reaction. Ensuing cyclotrimerization of diyne $\mathbf{5}$ with pivaloyl cyanide under the standard conditions ${ }^{[28]}(\mathrm{Cp} * \mathrm{RuCl}(\mathrm{cod})$ $(10 \mathrm{~mol} \%)$, dichloroethane, $\left.20^{\circ} \mathrm{C}\right)$ provided a mixture 
of two regioisomers $\mathbf{6 a}$ and $\mathbf{6 b}$ in 3.5:1 ratio furnishing the former in $56 \%$ and the latter in $15 \%$ isolated yields. As expected, the desired regioisomer $6 \mathbf{a}$ was formed preferentially. Unfortunately, the use of a simpler starting material such as 1-bromo-1,6-heptadiyne was not feasible, because of undesirable homocyclotrimerization. The TMS-group was then removed by treatment with tetrabutylammonium fluoride yielding ketone 7 (94\%). It was necessary to remove the TMS-group prior to the reduction of the carbonyl, because its steric hindrance hampered the reaction. Ketone 7 was then reduced by enantioselective transfer hydrogenation catalyzed by $\operatorname{RuCl}[(S, S)$-Tsdpen $](p$ cymene $)^{[9]}$ to the chiral alcohol $8(96 \%, 94 \%$ ee $)$. Its absolute $S$ configuration was unequivocally confirmed by a single crystal X-ray analysis ${ }^{[29]}$ (Figure 4 ).
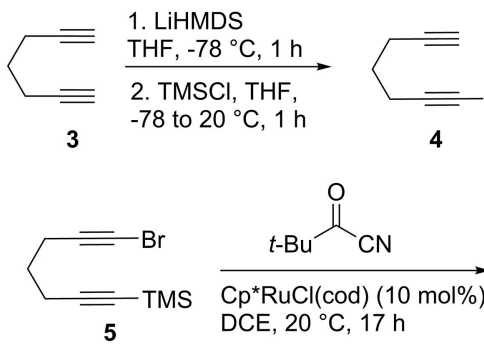
DCE
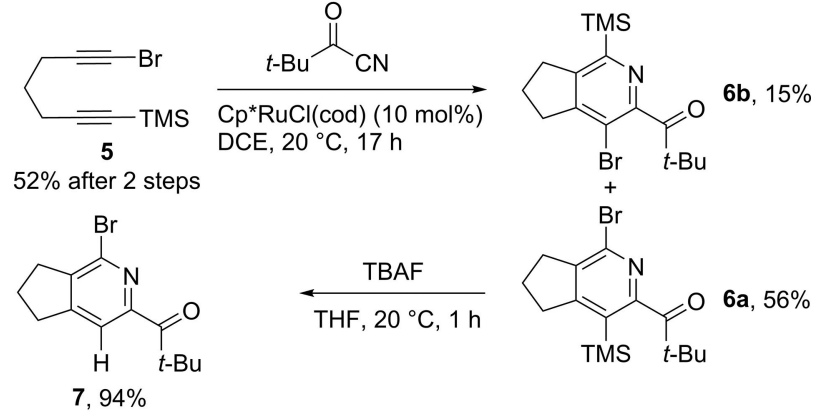

\begin{tabular}{|c}
$\begin{array}{c}\mathrm{RuCl}[(S, S)-T s d p e n](p-c y m e n e) \\
(5 \mathrm{~mol} \%)\end{array}$ \\
$\mathrm{HCOOH}, \mathrm{Et}_{3} \mathrm{~N}, \mathrm{DCM}, 20{ }^{\circ} \mathrm{C}$
\end{tabular}

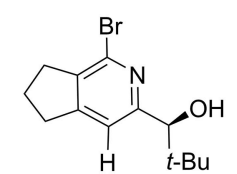

(S)-8, 96\%, 94\% ee

Scheme 2. Synthesis of $(S)-\mathbf{8}$.

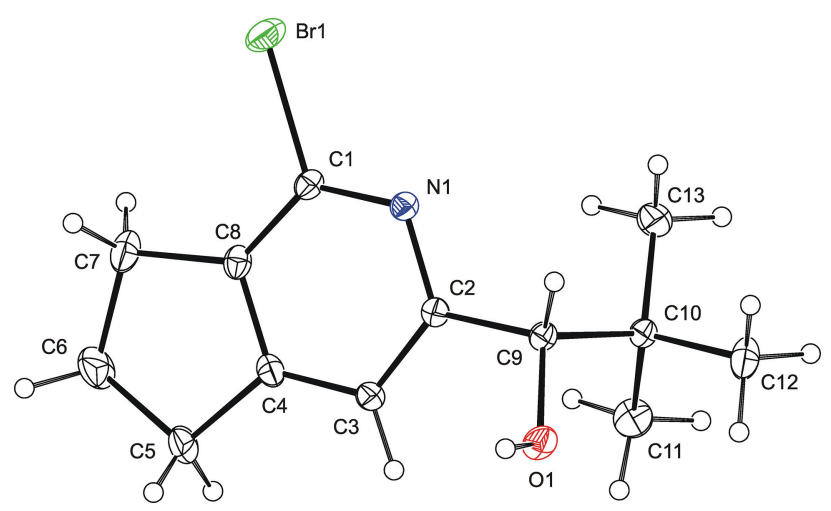

Figure 4. View on the molecule of $\mathbf{8}$. Displacement ellipsoids are drawn on $30 \%$ probability level.
The crucial step of the whole pathway to bipyridine $\mathbf{2}$ was the reductive dimerization of $(S)-\mathbf{8}$. Although, a plethora of various conditions for homocoupling of pyridines has been reported, they mainly deal with simple 2-halopyridines. ${ }^{[30]}$ Moreover, it was observed that yields were highly dependent on the structure of the starting halopyridine. Out of a number of available reaction conditions four best (in terms of yields) were selected to screen the homocoupling of $(S)-8$ (Table 1). Among these belong: a) Pd(0)-catalyzed homocoupling by using $\mathrm{Pd}(\mathrm{II}) /$ tetrakis(dimethylamino) ethylene (TDAE) (Entry 1) the original method used by Kobayashi et al. in the synthesis of Bolm's ligand 1:[9] b) Pd-catalyzed cross-coupling of the in situ generated tributylstannyl pyridine (Entry 2); ${ }^{[31]} \mathrm{c}$ ) $\mathrm{Ni}(0)$-catalyzed dimerization by using a mixture of $\mathrm{NiBr}_{2}\left(\mathrm{PPh}_{3}\right)_{2} / \mathrm{Zn} / \mathrm{Bu}_{4} \mathrm{NI}$ in THF (Entry 3$) ;^{[32]}$ and finally, d) $\mathrm{Ni}(0)$-catalyzed coupling by using a mixture of $\mathrm{NiCl}_{2} / \mathrm{Zn} / \mathrm{PPh}_{3}$ in DMF (Entry 4), the original method used by Bolm et al. in the first synthesis of bipyridine $\mathbf{1}^{[8]}$

In all cases, the main side product was dehalogenated pyridine 9 (Table 1), the formation of this type of product was also observed in most of the published procedures. It should be noted that formation of the side product could be reduced by using carefully degassed solvents. The unexpected products were compounds $\mathbf{1 0}$ (formed when method b was used), and 11 (observed in method c) arising after coupling with butyl and phenyl group respectively. The highest HPLC yield $(50 \%)$ of compound 2 was obtained by $\mathrm{Ni}(0)$-catalyzed homodimerization (Entry 4), but because of the complicated separation, the product was isolated in just $35 \%$ yield.

Although in most of the publications studying the dimerization of similar compounds the tolerance of free hydroxyl groups is described, in our hands the reactions proceeded only in low to moderate yields (Entries 1-4 Table 1). We decided to study homocoupling of ketone $\mathbf{7}$ to diketone $\mathbf{1 2}$ with intent to reduce it to the diol afterwards. Homocouplings were carried out under the same reaction conditions as in the above mentioned cases (Table 2). The yields of diketone 12 obtained under the used conditions were improved in all cases and the best yield of 12 (70\% HPLC yield, $66 \%$ isolated yield) was obtained when the catalytic system composed of a mixture of $\mathrm{NiCl}_{2} / \mathrm{Zn} / \mathrm{PPh}_{3}$ was used (Entry 4). Surprisingly, the next step, proved to be more challenging.

Although the racemic reduction of diketone $\mathbf{1 2}$ by using $\mathrm{NaBH}_{4}$ provided a mixture of rac and meso product in $90 \%$ combined isolated yield (See SI), enantioselective reduction turned out to be more challenging (Table 3). Reduction with (-)- $-\mathrm{Ipc}_{2} \mathrm{BCl}$ brought about no conversion of the starting material (Entry 1). On the other hand, transfer hydrogenation by using $5 \mathrm{~mol} \%$ of $\mathrm{RuCl}[(S, S)$-Tsdpen $](p \text {-cymene })^{[9]}$ 
Table 1. Reductive dimerization of alcohol $(S)-\mathbf{8}$ to diol $(S)$-2.

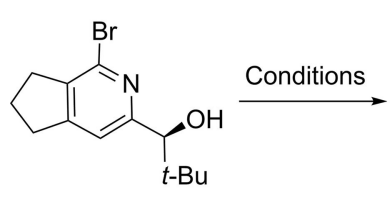

8

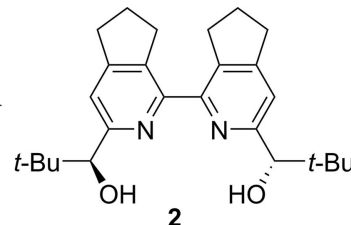

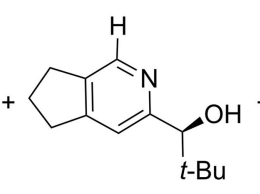

9

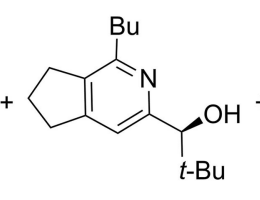

10

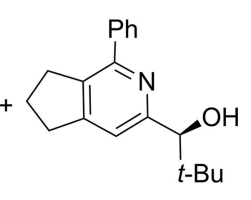

11

\begin{tabular}{|c|c|c|c|c|c|c|c|c|c|c|c|}
\hline \multirow[b]{2}{*}{ Entry } & \multirow[b]{2}{*}{ Catalyst } & \multirow[b]{2}{*}{$\mathrm{mol} \%$} & \multirow[b]{2}{*}{ Additives 1} & \multirow[b]{2}{*}{ Additives 2} & \multirow[b]{2}{*}{ Solvent } & \multirow[b]{2}{*}{$\mathrm{T}\left({ }^{\circ} \mathrm{C}\right)$} & \multirow[b]{2}{*}{$\mathrm{t}(\mathrm{h})$} & \multicolumn{4}{|c|}{ Yield $(\%)^{[\mathrm{a}]}$} \\
\hline & & & & & & & & 2 & 9 & 10 & 11 \\
\hline 1 & $\mathrm{PdCl}_{2}(\mathrm{PhCN})_{2}$ & 20 & & TDAE (2 eq.) & DMF & 80 & 120 & 30 & 60 & ND & ND \\
\hline 2 & $\mathrm{Pd}\left(\mathrm{PPh}_{3}\right)_{4}$ & $20+10$ & $(n-\mathrm{Bu})_{6} \mathrm{Sn}_{2}$ (1.15 eq.) & - & toluene & MW $150+180$ & $2+2$ & 10 & 35 & 35 & ND \\
\hline 3 & $\mathrm{NiBr}_{2}\left(\mathrm{PPh}_{3}\right)_{2}$ & 100 & $\mathrm{Zn}(5$ eq.) & $\mathrm{Bu}_{4} \mathrm{NI}$ (5 eq.) & THF & 60 & 48 & 20 & 60 & ND & 20 \\
\hline 4 & $\mathrm{NiCl}_{2}$ & 120 & Zn (1.3 eq.) & $\mathrm{PPh}_{3}$ (4.8 eq.) & $\mathrm{DMF}$ & 70 & 15 & $50(35)$ & 50 & ND & ND \\
\hline
\end{tabular}

${ }^{[a]}$ HPLC-yield (isolated yield). ND - not detected.

Table 2. Reductive dimerization of the ketone $\mathbf{7}$ to diketone $\mathbf{1 2}$.
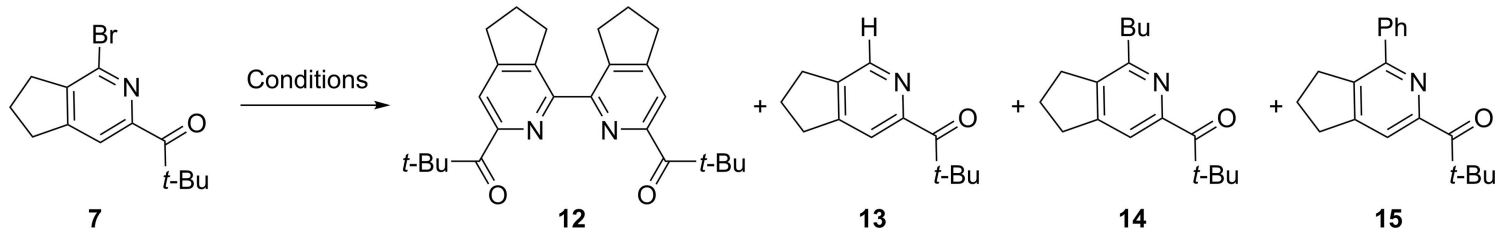

\begin{tabular}{|c|c|c|c|c|c|c|c|c|c|c|c|}
\hline \multirow[b]{2}{*}{ Entry } & \multirow[b]{2}{*}{ Catalyst } & \multirow[b]{2}{*}{$\mathrm{mol} \%$} & \multirow[b]{2}{*}{ Additives 1} & \multirow[b]{2}{*}{ Additives 2} & \multirow[b]{2}{*}{ Solvent } & \multirow[b]{2}{*}{$\mathrm{T}\left({ }^{\circ} \mathrm{C}\right)$} & \multirow[b]{2}{*}{$\mathrm{t}(\mathrm{h})$} & \multicolumn{4}{|c|}{ Yield $(\%)^{[\mathrm{a}]}$} \\
\hline & & & & & & & & 12 & 13 & 14 & 15 \\
\hline 1 & $\mathrm{PdCl}_{2}(\mathrm{PhCN})_{2}$ & 20 & & TDAE (2 eq.) & DMF & 80 & 120 & 50 & 50 & ND & ND \\
\hline 2 & $\mathrm{Pd}\left(\mathrm{PPh}_{3}\right)_{4}$ & $20+10$ & $(n-\mathrm{Bu})_{6} \mathrm{Sn}_{2}(1.15$ eq. $)$ & - & toluene & MW $150+180$ & $4+2$ & 20 & 30 & 20 & 20 \\
\hline 3 & $\mathrm{NiBr}_{2}\left(\mathrm{PPh}_{3}\right)_{2}$ & 100 & $\mathrm{Zn}(5$ eq.) & $\mathrm{Bu}_{4} \mathrm{NI}$ (5 eq.) & THF & 60 & 120 & 30 & 60 & ND & 10 \\
\hline 4 & $\mathrm{NiCl}_{2}$ & 120 & $\mathrm{Zn}$ (1.3 eq.) & $\mathrm{PPh}_{3}$ (4.8 eq.) & DMF & 70 & 16 & $70(66)$ & 30 & ND & ND \\
\hline
\end{tabular}

${ }^{[a]}$ HPLC-yield (isolated yield). ND - not detected.

and $\mathrm{HCOOH} / \mathrm{Et}_{3} \mathrm{~N}$ mixture at $20^{\circ} \mathrm{C}$ gave rise to product 16, in which only one of the ketone moieties was reduced (Entry 2). Both the higher amount of catalyst $(10 \mathrm{~mol} \%$, Entry 3$)$ and heating the reaction mixture to $40^{\circ} \mathrm{C}$ (Entries 3 and 4) provided compound $\mathbf{1 6}$ in higher yields ( $35 \%$ and $50 \%$, respectively), but only with traces of the desired diol $\mathbf{2}$. Increasing the temperature to $60^{\circ} \mathrm{C}$ along with $10 \mathrm{~mol} \%$ of the $\mathrm{Ru}-$ catalyst finally furnished the diol $\mathbf{2}$ in excellent enantiomeric excess (97\% ee), although only in a moderate yield of $48 \%$ (Entry 5).

The next strategy, for the synthesis of diol 2 in high yields, was based on homocoupling of the acetylprotected alcohol 17. Chiral alcohol 8 was protected to give $\mathbf{1 7}$ in $99 \%$ isolated yield under the standard conditions $\left(\mathrm{Ac}_{2} \mathrm{O}\right.$, pyridine $)$, then was homocoupled under the same four conditions as in the previous cases (Table 4 ). The best results were obtained again by Ni-catalyzed dimerization (Entry 4 ) furnishing the diacetate $\mathbf{1 8}$ in $68 \%$ isolated yield.

Deprotection of the hydroxyl groups gave the desired bipyridine diol $\mathbf{2}$ as an optically pure compound after isolation (Scheme 3). The $S, S$ stereo- chemistry of the furnished diol $\mathbf{2}$ was confirmed by a single crystal X-ray analysis ${ }^{[29,33]}$ (Figure 5).
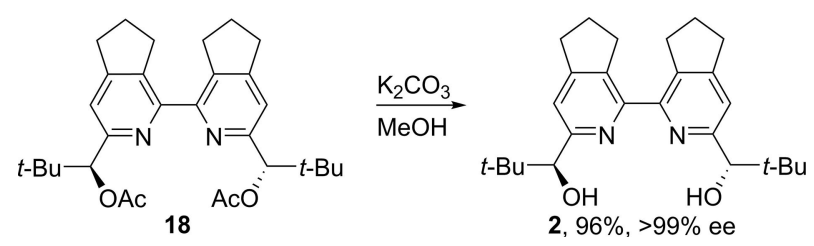

Scheme 3. Synthesis of the target compound $\mathbf{2}$ by deprotection of the diacetate $\mathbf{1 8}$.

We intended to determine the rotational barrier in compounds $\mathbf{2}$ and $\mathbf{1 2}$ by ${ }^{1} \mathrm{H}-\mathrm{NMR}$ spectroscopy, because of speculation that the barriers might be close to that of $2,2^{\prime}$-dimethylbiphenyl $\left(\Delta G^{\sharp}=18.1 \mathrm{kcal} / \mathrm{mol}\right.$ at $25^{\circ} \mathrm{C}$, see Figure SI-19). ${ }^{[3,35]}$

Although non-equivalency of the hydrogen atoms of the $\mathrm{CH}_{2}$ groups in $\mathbf{2}$ due to diastereotopicity was observed in the spectra of compound $\mathbf{2}$ (the result of the presence of centers of chirality in the molecule), 
Table 3. Transfer hydrogenation of the diketone $\mathbf{1 2}$ to diol $\mathbf{2 .}$

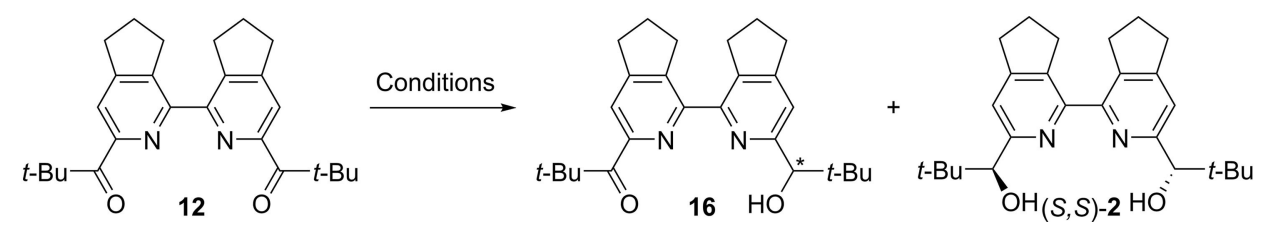

\begin{tabular}{|c|c|c|c|c|c|c|c|c|}
\hline Entry & Catalyst & $\mathrm{mol} \%$ & Reductant 1 & Solvent & $\mathrm{T}\left({ }^{\circ} \mathrm{C}\right)$ & $\mathrm{t}(\mathrm{h})$ & 16 & $\begin{array}{l}\text { Tield }(\%)^{[\mathrm{a}]} \\
\quad(S, \mathrm{~S})-\mathbf{2}\end{array}$ \\
\hline 1 & - & 20 & $(-)-\mathrm{Ipc}_{2} \mathrm{BCl}$ & THF & 20 & 120 & NR & NR \\
\hline 2 & $\operatorname{RuCl}[(S, S)$-Tsdpen $](p$-cymene $)$ & 5 & $\mathrm{HCOOH}, \mathrm{Et}_{3} \mathrm{~N}$ & - & 20 & 48 & 18 & ND \\
\hline 3 & $\operatorname{RuCl}[(S, S)$-Tsdpen $](p$-cymene $)$ & 10 & $\mathrm{HCOOH}, \mathrm{Et}_{3} \mathrm{~N}$ & $\mathrm{DCM}$ & 20 & 216 & $35^{[\mathrm{b}]}$ & traces \\
\hline 4 & $\operatorname{RuCl}[(S, S)$-Tsdpen $](p$-cymene $)$ & 10 & $\mathrm{HCOOH}, \mathrm{Et}_{3} \mathrm{~N}$ & DCM & 40 & 216 & $50^{[\mathrm{b}]}$ & traces \\
\hline 5 & $\operatorname{RuCl}[(S, S)$-Tsdpen $](p$-cymene $)$ & 10 & $\mathrm{HCOOH}, \mathrm{Et}_{3} \mathrm{~N}$ & DCM & 60 & 96 & 37 & 48 (97\% ee) \\
\hline
\end{tabular}

[a] Isolated yield unless otherwise noted. NR - no reaction; ND - not detected.

${ }^{[\mathrm{b}]}{ }^{1} \mathrm{H}-\mathrm{NMR}$ yield.

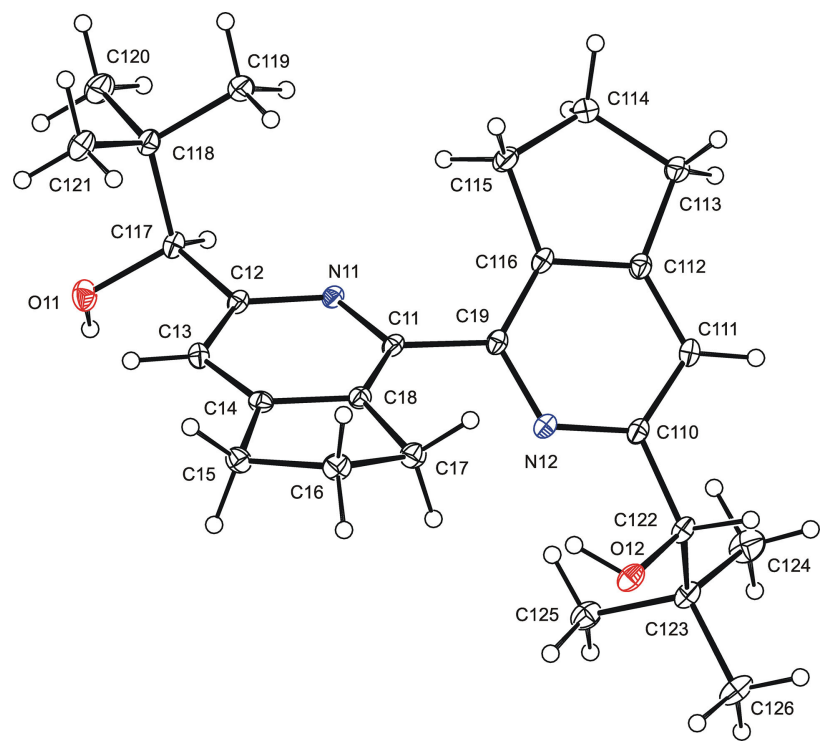

Figure 5. View on the molecule of 2. Displacement ellipsoids are drawn on $30 \%$ probability level.

no signal splitting due to the restricted rotation around the axis of chirality in ${ }^{1} \mathrm{H}-\mathrm{NMR}$ spectra of this compound as well as of compound $\mathbf{1 2}$ was observed even at $-80^{\circ} \mathrm{C}$ (Figure SI-19). This observation may be explained either by very low rotational barrier or by very small difference of resonance frequencies of the pairs of diastereotopic hydrogen atoms.

Because the ${ }^{1} \mathrm{H}-\mathrm{NMR}$ determination of rotational barriers in compounds $\mathbf{2}$ and $\mathbf{1 2}$ was not conclusive, we performed density functional theory (DFT) calculations of the barrier in compound 2 . For a validation of the computational method, we included calculations of the rotational barrier in 2,2'-dimethylbiphenyl. An energy scan upon the rotation around the biphenyl/ bipyridine main axis revealed a striking difference between compound $\mathbf{2}$ and 2,2'-dimethylbiphenyl (Fig- ure SI-20). While 2,2'-dimethylbiphenyl has a clear maximum, which has to be passed to achieve racemization, no such maximum is apparent in the scan of compound 2. On the other hand, the conformation with planar (antiperiplanar) arrangement of the two pyridine rings has minimal energy. This can be explained by stabilization due to extended conjugation in the planar conformation and at the same time, a decrease of steric hindrance due to missing hydrogen atoms in positions 1 and $1^{\prime}$ in bipyridine. These data are in agreement with previously reported calculations regarding rotational barrier of 2,2'-bipyridine. ${ }^{[36]}$ Optimization of the transition-state structure of the racemization in 2,2'-dimethylbiphenyl provided the rotational barrier of $16.7 \mathrm{kcal} / \mathrm{mol}$, which is reasonably close to the experimental value of $18.1 \mathrm{kcal} / \mathrm{mol}^{[34]}$

In order to acquire some information on chiral transition metal pre-catalyst, we tried to crystallize various transition metal salts $\left(\mathrm{FeBr}_{3}, \mathrm{Fe}\left(\mathrm{ClO}_{4}\right)_{2}\right.$, $\mathrm{Bi}(\mathrm{OTf})_{3}, \quad \mathrm{CoCl}_{2}, \quad\left[\mathrm{RuCl}_{2}(p \text {-cymene })\right]_{2}, \quad \mathrm{Cu}(\mathrm{OTf})_{2}$, $\left.\mathrm{Cu}\left(\mathrm{BF}_{4}\right)_{2}, \mathrm{CuCl}_{2},[\mathrm{CuCl}(\mathrm{cod})]_{2}, \mathrm{Cu}(\mathrm{MeCN})_{4} \mathrm{PF}_{6}\right)$ with 2. Out of these attempts only crystallizations with various $\mathrm{Cu}$ salts provided partially useful results. However, unlike the previous reports that described $\mathrm{Cu}$ complexes with $\mathbf{1}$ as monomeric species with square pyramidal, ${ }^{[37]}$ or trigonal bipyramidal ${ }^{[38]}$ geometry for $\mathrm{Cu}(\mathrm{II})$ or Y-shaped planar $^{[38]}$ geometry for $\mathrm{Cu}(\mathrm{I})$, we obtained different types of species. Thus the crystallization of $[\mathrm{CuCl}(\mathrm{cod})]_{2}$ with 2 provided light green crystals suitable for X-ray analysis. Interestingly, unlike in other cases of Bolm's ligand $\mathrm{Cu}$-complexes, a cluster composed of four $\mathrm{Cu}$ atoms and two ligands 2 CuCl was obtained ${ }^{[29]}$ (Figure 6). In addition, green crystals 2-CuX1 were obtained from other crystallization attempts with $\mathrm{CuCl}_{2}$. It was also a cluster, but with tetragonal geometry, in which four $\mathrm{Cu}$ atoms were coordinated to the chloride anion (Figure SI-25). In a similar manner blue crystals were obtained by 

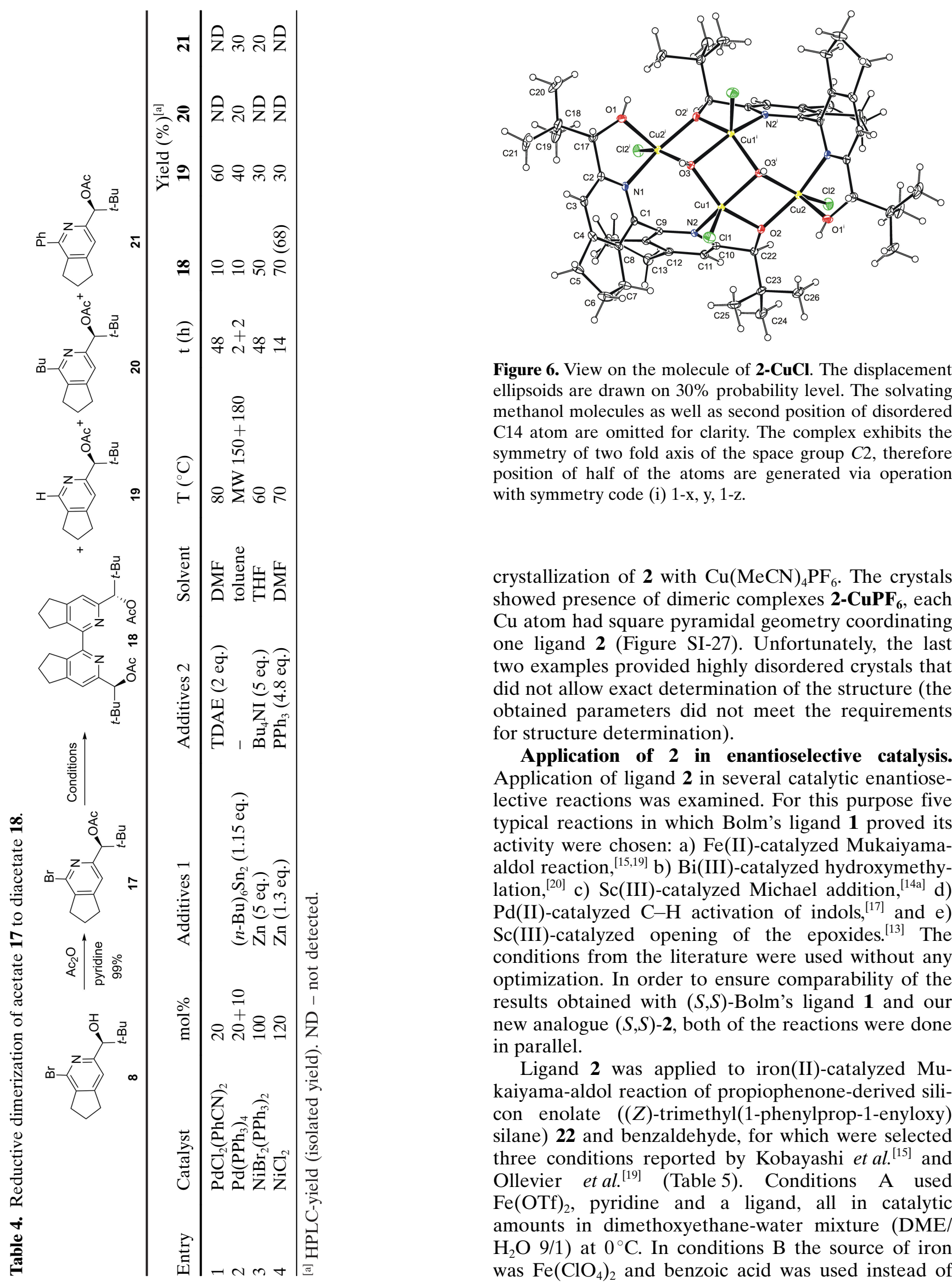

Figure 6. View on the molecule of 2-CuCl. The displacement ellipsoids are drawn on $30 \%$ probability level. The solvating methanol molecules as well as second position of disordered $\mathrm{C} 14$ atom are omitted for clarity. The complex exhibits the symmetry of two fold axis of the space group $C 2$, therefore position of half of the atoms are generated via operation with symmetry code (i) 1-x, y, 1-z.

crystallization of 2 with $\mathrm{Cu}(\mathrm{MeCN})_{4} \mathrm{PF}_{6}$. The crystals showed presence of dimeric complexes $\mathbf{2}-\mathbf{C u P F}_{\mathbf{6}}$, each $\mathrm{Cu}$ atom had square pyramidal geometry coordinating one ligand 2 (Figure SI-27). Unfortunately, the last two examples provided highly disordered crystals that did not allow exact determination of the structure (the obtained parameters did not meet the requirements for structure determination).

Application of 2 in enantioselective catalysis. Application of ligand $\mathbf{2}$ in several catalytic enantioselective reactions was examined. For this purpose five typical reactions in which Bolm's ligand $\mathbf{1}$ proved its activity were chosen: a) $\mathrm{Fe}(\mathrm{II})$-catalyzed Mukaiyamaaldol reaction, ${ }^{[15,19]}$ b) $\mathrm{Bi}(\mathrm{III})$-catalyzed hydroxymethylation, ${ }^{[20]}$ c) $\mathrm{Sc}(\mathrm{III})$-catalyzed Michael addition, ${ }^{[14 a]}$ d) $\mathrm{Pd}(\mathrm{II})$-catalyzed $\mathrm{C}-\mathrm{H}$ activation of indols, ${ }^{[17]}$ and e) Sc(III)-catalyzed opening of the epoxides. ${ }^{[13]}$ The conditions from the literature were used without any optimization. In order to ensure comparability of the results obtained with $(S, S)$-Bolm's ligand $\mathbf{1}$ and our new analogue $(S, S)$-2, both of the reactions were done in parallel.

Ligand 2 was applied to iron(II)-catalyzed $\mathrm{Mu}$ kaiyama-aldol reaction of propiophenone-derived silicon enolate (( $Z)$-trimethyl(1-phenylprop-1-enyloxy) silane) 22 and benzaldehyde, for which were selected three conditions reported by Kobayashi et al. ${ }^{[15]}$ and Ollevier et al. ${ }^{[19]}$ (Table 5). Conditions A used $\mathrm{Fe}(\mathrm{OTf})_{2}$, pyridine and a ligand, all in catalytic amounts in dimethoxyethane-water mixture (DME/ $\left.\mathrm{H}_{2} \mathrm{O} 9 / 1\right)$ at $0{ }^{\circ} \mathrm{C}$. In conditions B the source of iron was $\mathrm{Fe}\left(\mathrm{ClO}_{4}\right)_{2}$ and benzoic acid was used instead of 
pyridine in $\mathrm{DME} / \mathrm{H}_{2} \mathrm{O} 7 / 3$. In conditions $\mathrm{C}$ were used $\mathrm{Fe}(\mathrm{II})$ dodecylsulfate $\left(\mathrm{Fe}(\mathrm{DS})_{2}\right)$, benzoic acid and a ligand in pure water at $20^{\circ} \mathrm{C}$. The reaction under conditions A with ligand $\mathbf{2}$ proceeded to give the corresponding aldol product $\mathbf{2 3}$ in quantitative yield with excellent diastereoselectivity (99/1) and very high enantioselectivity of $92 \%$ ee (Entry 3 ). The results were comparable with the reported results obtained by using Bolm's ligand $\mathbf{1}^{[15]}$ (Entry 1 ) or that carried out by us (Entry 2). The reaction was performed under conditions B by using ligand 2 provided aldol 23 in quantitative yield, good diastereoselectivity (98/2) and a good enantioselectivity of $90 \%$ ee (Entry 6 ) that were almost same as by using Bolm's ligand (Entries 4 and 5). It should be emphasized, that during the course of this study we found that the results of aldol reaction carried out with Bolm's ligand $\mathbf{1}$ were highly sensitive to the purity of all reactants. In order to achieve reproducible results all reactants had to be meticulously purified prior to the reactions. This can be nicely exemplified by comparison of reactions carried out with the reactants purified (distilled) prior to the reactions (see Entries 1-6) with those used as purchased (see Entries 7-10). Interestingly, the decrease in enantioselectivity was more pronounced in the cases when ligand $\mathbf{1}$ was used, than in cases when ligand 2 was used.

By using conditions $\mathrm{C}$ the published level of selectivity (dr 91/9, 92\% ee) with Bolm's ligand $\mathbf{1}$ was not achieved and $\mathbf{2 3}$ was obtained in $\mathrm{dr} 88 / 12$ and $84 \%$ ee (Entries 11 and 12$){ }^{[19]}$ This could be attributed to difficulties encountered during the preparation of $\mathrm{Fe}(\mathrm{DS})_{2}$. Gratifyingly, the use of ligand $\mathbf{2}$ gave aldol $\mathbf{2 3}$ with better diastereoselectivity (93/7) and enantioselectivity ( $88 \%$ ee) (Entry 13).

The second application was $\mathrm{Bi}(\mathrm{III})$-catalyzed hydroxymethylation of the same silicon enolate 22 with formaldehyde (Table 6) ${ }^{[20]}$ By using ligand $\mathbf{2}$, product

Table 6. Bi(III)-catalyzed hydroxymethylation of silicon enolate 22 with formaldehyde in the presence of Bolm's ligand $\mathbf{1}$ and ligand $\mathbf{2}$.

\begin{tabular}{llll} 
Entry & Ligand & Yield $(\%)^{[\mathrm{a}]}$ & ee $(\%)^{[\mathrm{b}, \mathrm{c}]}$ \\
\hline $1^{[\mathrm{d}]}$ & $(S, S)-\mathbf{1}$ & 93 & 91 \\
2 & $(S, S)-\mathbf{1}$ & $>96$ & 89 \\
3 & $(S, S)-\mathbf{2}$ & $>96$ & 86 \\
\hline
\end{tabular}

${ }^{[a]}$ Isolated yields.

${ }^{[b]}$ Determined by HPLC with a chiral stationary phase.

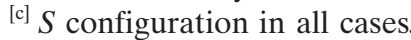

${ }^{[\mathrm{d}]}$ Data reported in ref. [20].
Table 5. Fe(II)-catalyzed Mukaiyama-aldol reaction of silicon enolate $\mathbf{2 2}$ and benzaldehyde in the presence of Bolm's ligand $\mathbf{1}$ and ligand $\mathbf{2}$.

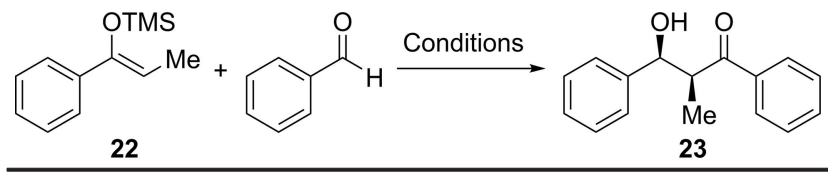

\begin{tabular}{lllll}
\hline Entry & Cond. $^{[\mathrm{a}]}$ & $\begin{array}{c}\text { Ligand Yield } \\
(\%)^{[\mathrm{b}]}\end{array}$ & $\begin{array}{l}\mathrm{dr}(\text { syn/ } \\
\text { anti })^{[\mathrm{c}]}\end{array}$ & $\begin{array}{l}\text { ee }(\%)^{[\mathrm{d}, \mathrm{e}]} \\
(\text { syn })^{)}\end{array}$ \\
\hline $1^{[\mathrm{f}]}$ & $\mathrm{A}$ & $(S, S)-\mathbf{1} 90$ & $97 / 3$ & 91 \\
2 & $\mathrm{~A}$ & $(S, S)-\mathbf{1}>96^{[\mathrm{c}]}$ & $97 / 3$ & 93 \\
3 & $\mathrm{~A}$ & $(S, S)-\mathbf{2}>96$ & $99 / 1$ & 92 \\
$4^{[\mathrm{f}]}$ & $\mathrm{B}$ & $(S, S)-\mathbf{1} 85$ & $97 / 3$ & 88 \\
5 & $\mathrm{~B}$ & $(S, S)-\mathbf{1} 95^{[\mathrm{c}]}$ & $97 / 3$ & 91 \\
6 & $\mathrm{~B}$ & $(S, S)-\mathbf{2}>96$ & $98 / 2$ & 90 \\
$7^{[\mathrm{g}]}$ & $\mathrm{A}$ & $(S, S)-\mathbf{1}>96^{[\mathrm{c}]}$ & $95 / 5$ & 86 \\
$8^{[\mathrm{g}]}$ & $\mathrm{A}$ & $(S, S)-\mathbf{2} 96$ & $97 / 3$ & 92 \\
$9^{[\mathrm{g}]}$ & $\mathrm{B}$ & $(S, S)-\mathbf{1}>96^{[\mathrm{c}]}$ & $96 / 4$ & 76 \\
$10^{[\mathrm{g}]}$ & $\mathrm{B}$ & $(S, S)-\mathbf{2} 90$ & $97 / 3$ & 83 \\
$11^{[\mathrm{h}]}$ & $\mathrm{C}$ & $(S, S)-\mathbf{1} 80$ & $91 / 9$ & 92 \\
12 & $\mathrm{C}$ & $(S, S)-\mathbf{1} 88^{[\mathrm{c}]}$ & $88 / 12$ & 84 \\
13 & $\mathrm{C}$ & $(S, S)-\mathbf{2} 87$ & $93 / 7$ & 88 \\
\hline
\end{tabular}

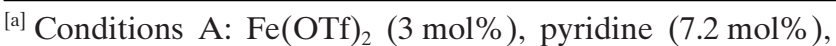
ligand $(3.6 \mathrm{~mol} \%), \mathrm{DME} / \mathrm{H}_{2} \mathrm{O} 9 / 1,0{ }^{\circ} \mathrm{C}^{[15]}$ Conditions $\mathrm{B}$ : $\mathrm{Fe}\left(\mathrm{ClO}_{4}\right)_{2}(3 \mathrm{~mol} \%)$, $\mathrm{PhCOOH}(3.6 \mathrm{~mol} \%)$, ligand (3.6 mol\% ), DME/ $\mathrm{H}_{2} \mathrm{O} 7 / 3,0{ }^{\circ} \mathrm{C} .{ }^{[15]}$ Conditions C: $\mathrm{Fe}(\mathrm{DS})_{2}$ (5 mol\%), $\mathrm{PhCOOH}(5 \mathrm{~mol} \%)$, ligand (15 mol\%), $\mathrm{H}_{2} \mathrm{O}$, $20{ }^{\circ} \mathrm{C}^{[19]}$

${ }^{[b]}$ Isolated yields unless otherwise noted.

[c] Determined by ${ }^{1} \mathrm{H}-\mathrm{NMR}$.

[d] Determined by HPLC with a chiral stationary phase.

${ }^{\text {[e] }} S, S$ configuration in all cases.

${ }^{[\mathrm{f}]}$ Data reported in ref. [15].

${ }^{[g]}$ Reactants were not purified prior to the reaction.

${ }^{[\mathrm{h}]}$ Data reported in ref. [19].

24 was furnished in quantitative yield and $86 \%$ ee (Entry 3) a result similar to the one obtained with Bolm's ligand (Entry 2).

Ligand 2 was also used in Sc(III)-catalyzed Michael addition of $\beta$-ketoester $\mathbf{2 5}$ to methyl vinyl ketone (MVK) in dichloromethane (Table 7). ${ }^{[14]}$ The Michael adduct 26 was obtained in quantitative yield and $81 \%$ ee (Entry 3 ), while using Bolm's ligand $\mathbf{1}$ its yield was $94 \%$ and $90 \%$ ee (Entry 2). However, without drying of $\mathrm{Sc}(\mathrm{III})$ triflate and distillation of MVK prior to use ee dropped to $67 \%$ (Entry 4). On the other hand, under the same conditions using ligand 2 ee remained unchanged at $81 \%$ (Entry 5).

Ligand 2 was also tested in $\mathrm{C}-\mathrm{H}$ activation of indol $\mathbf{2 7}$ followed by conjugated addition to $\mathbf{2 8}$ catalyzed by $\operatorname{Pd}(\mathrm{II})$ in the presence of dodecyl sulfate salt in water (Table 8). ${ }^{[17]}$ In this case were the yield and ee of product 29 noticeably lower (69\%, 72\% ee, Entry 3) compared to the use of Bolm's ligand (94\%, $89 \%$ ee, Entry 2). 
Table 7. Sc(III)-catalyzed Michael addition of $\beta$-ketoester 25 and MVK in the presence of Bolm's ligand $\mathbf{1}$ and ligand 2.

\begin{tabular}{llll}
\hline & & & \\
Entry & Ligand & Yield $(\%)^{[\mathrm{a}]}$ & ee $(\%)^{[\mathrm{b}, \mathrm{c}]}$ \\
\hline $1^{[\mathrm{d}]}$ & $(S, S)-\mathbf{1}$ & 94 & 92 \\
2 & $(S, S)-\mathbf{1}$ & $94^{[\mathrm{e}]}$ & 90 \\
3 & $(S, S)-\mathbf{2}$ & $>96$ & 81 \\
$4^{[\mathrm{f}]}$ & $(S, S)-\mathbf{1}$ & $>96$ & 67 \\
$5^{[\mathrm{f}]}$ & $(S, S)-\mathbf{2}$ & $>96$ & 81 \\
\hline
\end{tabular}

${ }^{[a]}$ Isolated yields unless otherwise noted.

${ }^{[b]}$ Determined by HPLC with a chiral stationary phase.

${ }^{[c]} R$ configuration in all cases.

${ }^{[d]}$ Data reported in ref. [14a].

${ }^{[\mathrm{e}]}{ }^{1} \mathrm{H}-\mathrm{NMR}$ yield.

${ }^{[\mathrm{f}]}$ Reactants were not purified prior to the reaction.

Table 8. Pd(II)-catalyzed C-H activation of indol 27 in the presence of Bolm's ligand $\mathbf{1}$ and ligand $\mathbf{2}$.

\begin{tabular}{|c|c|c|c|}
\hline 27 & $2 \varepsilon$ & $\begin{array}{c}\mathrm{PdCl}_{2}(5 \mathrm{~mol} \%) \\
\mathrm{NaDS}^{(10 \mathrm{~mol} \%)} \\
\begin{array}{c}\text { Ligand }(6 \mathrm{~mol} \%) \\
\mathrm{PhNMe}_{2}(12 \mathrm{~mol} \%) \\
\mathrm{H}_{2} \mathrm{O}, 20^{\circ} \mathrm{C}\end{array}\end{array}$ & $\prod_{\mathrm{H}}^{\mathrm{Me}}$ \\
\hline Entry & Ligand & Yield (\%) $)^{[a]}$ & ee $(\%)^{[b, c]}$ \\
\hline $1^{[\mathrm{d}]}$ & $(S, S)-\mathbf{1}$ & 94 & 92 \\
\hline 2 & $(S, S)-\mathbf{1}$ & $94^{[\mathrm{e}]}$ & 89 \\
\hline 3 & $(S, S)-\mathbf{2}$ & 69 & 72 \\
\hline
\end{tabular}

[a] Isolated yields unless otherwise noted.

${ }^{[b]}$ Determined by HPLC with a chiral stationary phase.

${ }^{[c]} R$ configuration in all cases.

${ }^{[d]}$ Data reported in ref. [17].

${ }^{[e]}{ }^{1} \mathrm{H}-\mathrm{NMR}$ yields.

Last but not least, the activity of ligand $\mathbf{2}$ was also tested in Sc(III)-catalyzed epoxide ring opening of cisstilbene oxide $\mathbf{3 0}$ by $p$-methoxybenzyl alcohol in dichloromethane (Table 9). ${ }^{[13]}$ By using Bolm's ligand $\mathbf{1}$, product 31 was obtained with $90 \%$ yield $\left({ }^{1} \mathrm{H}-\mathrm{NMR}\right)$ and $95 \%$ ee while using ligand $\mathbf{2}$, product $\mathbf{3 1}$ was obtained in $82 \%$ isolated yield and with excellent enantioselectivity of $98 \%$.

\section{Conclusion}

We have demonstrated that Ru-catalyzed cyclotrimerization of a 1-halodiyne with nitriles is a suitable reaction allowing preparation of substituted pyridines. Specifically, cyclotrimerization of (7-bromohepta-1,6diyn-1-yl)trimethylsilane with pivaloyl cyanide provides regioselectively 1-bromo-6,7-dihydro-5 $H$-cyclopenta $[c]$ pyridine that can be easily converted into
Table 9. Sc(III)-catalyzed ring opening of cis-stilbene oxide $\mathbf{3 0}$ in the presence of Bolm's ligand $\mathbf{1}$ and ligand $\mathbf{2}$.

\begin{tabular}{llll} 
Entry & Ligand & Yield $(\%)^{[\mathrm{a}]}$ & ee $(\%)^{[\mathrm{b}, \mathrm{c}]}$ \\
\hline $1^{[\mathrm{d}]}$ & $(R, R)-\mathbf{1}$ & 82 & $97^{[\mathrm{e}]}$ \\
2 & $(S, S)-\mathbf{1}$ & $90^{[\mathrm{f}]}$ & 95 \\
3 & $(S, S)-\mathbf{2}$ & 82 & 98 \\
\hline
\end{tabular}

[a] Isolated yields unless otherwise noted.

${ }^{[b]}$ Determined by HPLC with a chiral stationary phase.

${ }^{[c]} S, S$ configuration unless otherwise noted.

${ }^{[\mathrm{d}]}$ Data reported in ref. [13].

${ }^{[\mathrm{e}]} R, R$ configuration.

[f] ${ }^{1} \mathrm{H}-\mathrm{NMR}$ yields.

Bolm's ligand analog 2. One of the crucial steps along the synthetic route was homodimerization of the bromopyridine that was optimized to give a bipyridine intermediate in high yield.

As far as the use of $\mathbf{2}$ as ligand in enantioselective reactions is concerned, the results indicate its potential applicability. Although the use of $\mathbf{2}$ in hydroxymethylation, Michael addition, and $\mathrm{C}-\mathrm{H}$ activation gave products with lower enantioselectivity than the reported values obtained with Bolm's ligand 1, other reactions were more promising. The use of $\mathbf{2}$ in aldol reaction gave products within the same range of enantioselectivity as Bolm's ligand 1. However, it should be pointed out that $\mathbf{2}$ is more robust, because it gave exactly the same results with reactants that were not purified prior to the reaction. In this instance the use of Bolm's ligand $\mathbf{1}$ gave products with decreased enantioselectivity by $6-7 \%$ ee. Its robustness was also noticed in the case of Michael addition with reactants that were not purified where the product was obtained with enantioselectivity of $81 \%$ ee, whereas with 1 the obtained ee was $67 \%$. Gratifyingly, in the ring opening of epoxides it gave products with slightly higher enantioselectivity of $98 \%$ ee (95\% ee with $\mathbf{1}$ in our hand, $97 \%$ ee the reported value).

\section{Experimental Section}

1-(1-Bromo-4-(trimethylsilyl)-6,7-dihydro-5H-cyclopenta[c] pyridin-3-yl)-2,2-dimethylpropan-1-one (6a) and 1-(4-bromo1-(trimethylsilyl)-6,7-dihydro-5H-cyclopenta[c]pyridin-3-yl)2,2-dimethylpropan-1-one (6b). To a dried argon flushed $50 \mathrm{~mL}$ flask with $\mathrm{Cp} * \mathrm{RuCl}(\mathrm{COD})(110 \mathrm{mg}, 0.29 \mathrm{mmol})$, DCE $(14 \mathrm{ml})$ followed by pivaloyl cyanide $(0.7 \mathrm{ml}, 5.8 \mathrm{mmol})$ were added. Then diyne 5 (700 $\mathrm{mg}, 2.9 \mathrm{mmol})$ dissolved in DCE $(18 \mathrm{~mL})$ was added slowly by the syringe pump during the course of 1 hour and the reaction mixture was stirred at $20^{\circ} \mathrm{C}$ After the consumption of $\mathbf{5}$ (disappearance of the 
respective spot on TLC), volatiles were evaporated under reduced pressure. Column chromatography of the residue on silica gel (gradient 10/1 $\rightarrow 2 / 1$ hexanes/DCM) provided $566 \mathrm{mg}(\mathbf{6 a}, 56 \%)$ and $151 \mathrm{mg}(\mathbf{6 b}, 15 \%)$ of the title compounds as colorless solids.

6a: $\mathrm{Mp}=65.7^{\circ} \mathrm{C} \cdot{ }^{1} \mathrm{H}-\mathrm{NMR}\left(300 \mathrm{MHz}, \mathrm{CDCl}_{3}\right) \delta 3.09(\mathrm{t}, J=$ $\left.7.6 \mathrm{~Hz}, 2 \mathrm{H}, \mathrm{CH}_{2}\right), 2.92\left(\mathrm{t}, J=7.6 \mathrm{~Hz}, 2 \mathrm{H}, \mathrm{CH}_{2}\right), 2.06(\mathrm{p}, J=$ $\left.7.6 \mathrm{~Hz}, 2 \mathrm{H}, \mathrm{CH}_{2}\right), 1.41\left(\mathrm{~s}, 9 \mathrm{H}, 3 \times \mathrm{CH}_{3}\right), 0.28\left(\mathrm{~s}, 9 \mathrm{H}, 3 \times \mathrm{CH}_{3}\right)$. ${ }^{13} \mathrm{C}-\mathrm{NMR}\left(75 \mathrm{MHz}, \mathrm{CDCl}_{3}\right) \delta 210.59,162.76,161.12,141.90$, 137.81, 130.33, 44.17, 36.91, 32.79, 28.31, 23.64, 1.69. IR (drift $\mathrm{KBr}) v_{\max } 2956,1681,1520,1249,1054,919,901,845 \mathrm{~cm}^{-1}$. HRMS (ESI) $\mathrm{m} / z$ calculated for $\mathrm{C}_{14} \mathrm{H}_{25} \mathrm{NOBrSi}(\mathrm{M}+\mathrm{H})$ 354.0889 , found 354.0889. $\mathrm{R}_{\mathrm{f}}(20 / 1$ hexane/EtOAc $)=0.38$.

(S)-1-(1-Bromo-6,7-dihydro-5H-cyclopenta[c]pyridin-3-yl)2,2-dimethylpropan-1-ol (8). To a dried argon flushed $10 \mathrm{~mL}$ flask with solution of 7 (332 $\mathrm{mg}, 1.2 \mathrm{mmol})$ and $\operatorname{RuCl}[(S, S)$ Tsdpen](p-cymene) (40 mg, $0.06 \mathrm{mmol})$ in DCM (1 mL), 2/1 mixture of $\mathrm{Et}_{3} \mathrm{~N} / \mathrm{HCOOH}(1.8 \mathrm{~mL})$ was added. After stirring for 3 days at $20^{\circ} \mathrm{C}$, the reaction was quenched with water $(10 \mathrm{~mL})$ and extracted with EtOAc $(3 \times 30 \mathrm{~mL})$. The combined organic layers were dried over $\mathrm{MgSO}_{4}$, filtered and concentrated under reduced pressure. Column chromatography of the residue on silica gel (gradient $10 / 1 \rightarrow 7 / 1$ hexanes/ EtOAc) furnished $319 \mathrm{mg}(96 \%, 94 \%$ ee $)$ of the title compound $\mathbf{8}$ as an amorphous solid. Optically pure compound could be obtained by crystallization from $\mathrm{CHCl}_{3}$ by slow evaporation of solvent.

M.p. $=65.9^{\circ} \mathrm{C} .{ }^{1} \mathrm{H}-\mathrm{NMR}\left(400 \mathrm{MHz}, \mathrm{CDCl}_{3}\right) \delta 7.01(\mathrm{~s}, 1 \mathrm{H}$, $\mathrm{Ar}-\mathrm{H}), 4.27(\mathrm{~s}, 1 \mathrm{H}, \mathrm{CH}), 3.60$ (brs, $1 \mathrm{H}, \mathrm{OH}), 3.00(\mathrm{t}, J=$ $\left.7.6 \mathrm{~Hz}, 2 \mathrm{H}, \mathrm{CH}_{2}\right), 2.92\left(\mathrm{t}, J=7.6 \mathrm{~Hz}, 2 \mathrm{H}, \mathrm{CH}_{2}\right), 2.13(\mathrm{p}, J=$ $\left.7.6 \mathrm{~Hz}, 2 \mathrm{H}, \mathrm{CH}_{2}\right), 0.90\left(\mathrm{~s}, 9 \mathrm{H}, 3 \times \mathrm{CH}_{3}\right) .{ }^{13} \mathrm{C}-\mathrm{NMR}(100 \mathrm{MHz}$, $\left.\mathrm{CDCl}_{3}\right) \delta 159.75,155.84,140.65,137.61,118.37,80.47,36.36$, 33.91, 32.84, 26.01, 23.75. IR (drift KBr) $v_{\max } 2956,2903$, $1598,1541,1453,1415,1364,1238,1108,1063,1016 \mathrm{~cm}^{-1}$. HRMS (ESI) $\mathrm{m} / z$ calculated for $\mathrm{C}_{13} \mathrm{H}_{18} \mathrm{BrNO}$ (M) 283.0572, found 283.0580. $\mathrm{R}_{\mathrm{f}}(10 / 1$ hexane/EtOAc $)=0.28 . \quad[\alpha]_{D}^{20}=+$ $1.52^{\circ}\left(\mathrm{CHCl}_{3}, c=2.62 \mathrm{~g} / 100 \mathrm{~mL}\right)$

(S,S)-(6,6', 7,7'-Tetrahydro-5H,5'H-[1,1'-bi(cyclopenta[c] pyridine)]-3,3'-diyl)bis(2,2-dimethylpropane-1,1-diyl) diacetate (18). To a dry argon flushed $100 \mathrm{~mL}$ flask with $\mathrm{NiCl}_{2}$ (305 mg, $2.3 \mathrm{mmol}$ ) dry degassed DMF (13.5 mL) was added. The mixture was heated to $70^{\circ} \mathrm{C}$, then $\mathrm{PPh}_{3}(2.4 \mathrm{~g}$, $9.24 \mathrm{mmol})$ and $\mathrm{Zn}(166 \mathrm{mg}, 2.5 \mathrm{mmol})$ were added. The reaction mixture was stirred at $70^{\circ} \mathrm{C}$ for 1 hour, then $\mathbf{1 7}$ (628 $\mathrm{mg}, 1.9 \mathrm{mmol})$ in dry degassed DMF $(13.5 \mathrm{~mL})$ was added. After stirring for 14 hours at $70^{\circ} \mathrm{C}$, the reaction mixture was quenched with water $(25 \mathrm{~mL})$ and extracted with $\mathrm{Et}_{2} \mathrm{O}(3 \times 100 \mathrm{~mL})$. The combined organic layers were washed with brine $(50 \mathrm{~mL})$, dried over $\mathrm{MgSO}_{4}$, filtered and concentrated under reduced pressure. Column chromatography of the residue on silica gel (gradient $20 / 1 \rightarrow 5 / 1$ hexanes/ EtOAc) furnished $321 \mathrm{mg}$ (68\%) of the title compound $\mathbf{1 8}$ as a colorless solid.

$\mathrm{Mp}=173.6^{\circ} \mathrm{C} .{ }^{1} \mathrm{H}-\mathrm{NMR}\left(400 \mathrm{MHz}, \mathrm{CDCl}_{3}\right) \delta 7.11(\mathrm{~s}, 2 \mathrm{H}, 2 \times$ $\mathrm{Ar}-\mathrm{H}), 5.56(\mathrm{~s}, 2 \mathrm{H}, 2 \times \mathrm{CH}), 3.49-3.38(\mathrm{~m}, 2 \mathrm{H}, 2 \times \mathrm{CH}), 3.14$ $3.03(\mathrm{~m}, 2 \mathrm{H}, 2 \times \mathrm{CH}), 2.92\left(\mathrm{t}, J=7.6 \mathrm{~Hz}, 4 \mathrm{H}, 2 \times \mathrm{CH}_{2}\right), 2.12(\mathrm{~s}$, $\left.6 \mathrm{H}, 2 \times \mathrm{CH}_{3}\right), 2.11-1.94\left(\mathrm{~m}, 4 \mathrm{H}, 2 \times \mathrm{CH}_{2}\right), 1.00(\mathrm{~s}, 18 \mathrm{H}, 6 \times$ $\left.\mathrm{CH}_{3}\right) .{ }^{13} \mathrm{C}-\mathrm{NMR}\left(100 \mathrm{MHz}, \mathrm{CDCl}_{3}\right) \delta 170.43,154.99,154.63$,
$152.27,138.88,117.76,84.08,35.16,33.01,32.99,26.53,24.99$, 21.32. IR (drift KBr) $v_{\max } 2959$, 2905, 2870, 1735, 1585, 1558, 1427, 1396, 1370, 1244, 1023, $972 \mathrm{~cm}^{-1}$. HRMS (ESI) $\mathrm{m} / z$ calculated for $\mathrm{C}_{30} \mathrm{H}_{41} \mathrm{~N}_{2} \mathrm{O}_{4} \quad(\mathrm{M}+\mathrm{H})$ 493.30608, found 493.30600. $\mathrm{R}_{\mathrm{f}}(10 / 1$ hexane/EtOAc $)=0.23$.

(S,S)-1,1'-(6,6', 7,7'-Tetrahydro-5H,5' H-[1,1'-bi(cyclopenta[c] pyridine)]-3,3'-diyl)bis(2,2-dimethylpropan-1-ol) $\quad((S, S)-2)$. To a solution of $321 \mathrm{mg}$ of $\mathbf{1 8}(321 \mathrm{mg}, 0.65 \mathrm{mmol})$ in $\mathrm{MeOH}$ $(5 \mathrm{~mL})$ in $25 \mathrm{~mL}$ flask, $\mathrm{K}_{2} \mathrm{CO}_{3}(675 \mathrm{mg}, 4.9 \mathrm{mmol})$ was added. After stirring of the mixture for 5 hours at $20^{\circ} \mathrm{C}$, the reaction was quenched with water and extracted with DCM $(4 \times$ $30 \mathrm{~mL}$ ). The combined organic layers were dried over $\mathrm{MgSO}_{4}$, filtered and concentrated under reduced pressure. Column chromatography of the residue on silica gel (gradient $5 / 1 \rightarrow 3 / 1$ hexanes/EtOAc) provided $254 \mathrm{mg}(96 \%$, $>99 \%$ ee) of the title compound $\mathbf{2}$ as colorless crystals.

$\mathrm{Mp}=214.0^{\circ} \mathrm{C} .{ }^{1} \mathrm{H}-\mathrm{NMR}\left(400 \mathrm{MHz}, \mathrm{CDCl}_{3}\right) \delta 7.09(\mathrm{~s}, 2 \mathrm{H}, 2 \times$ Ar-H), 4.71 (brs, $2 \mathrm{H}, 2 \times \mathrm{OH}), 4.38$ (s, $2 \mathrm{H}, 2 \times \mathrm{CH}), 3.37-3.27$ $(\mathrm{m}, 2 \mathrm{H}, 2 \times \mathrm{CH}), 3.25-3.15(\mathrm{~m}, 2 \mathrm{H}, 2 \times \mathrm{CH}), 2.97(\mathrm{t}, J=$ $\left.7.6 \mathrm{~Hz}, 4 \mathrm{H}, 2 \times \mathrm{CH}_{2}\right), 2.16-2.05\left(\mathrm{~m}, 4 \mathrm{H}, 2 \times \mathrm{CH}_{2}\right), 0.97(\mathrm{~s}$, $\left.18 \mathrm{H}, 6 \times \mathrm{CH}_{3}\right) .{ }^{13} \mathrm{C}-\mathrm{NMR}\left(100 \mathrm{MHz}, \mathrm{CDCl}_{3}\right) \delta 156.47,155.68$, 151.06, 138.76, 118.74, 80.50, 36.66, 33.10, 32.89, 26.29, 25.40. IR (drift KBr) $v_{\max } 2969,2870,1588,1558,1435,1363,1226$, 1066, 1051, $1014 \mathrm{~cm}^{-1}$. HRMS (ESI) $\mathrm{m} / \mathrm{z}$ calculated for $\mathrm{C}_{26} \mathrm{H}_{37} \mathrm{~N}_{2} \mathrm{O}_{2}(\mathrm{M}+\mathrm{H})$ 409.28495, found 409.28521. $\mathrm{R}_{\mathrm{f}}(3 / 1$ hexanes/EtOAc $)=0.33 . \quad[\alpha]_{D}^{20}=-20.5^{\circ} \quad\left(\mathrm{CHCl}_{3}, \quad c=0.367 \mathrm{~g} /\right.$ $100 \mathrm{~mL})$.

(1S,2S)-2-((4-Methoxybenzyl)oxy)-1,2-diphenylethan-1-ol (31). To a solution of $\mathrm{Sc}(\mathrm{OTf})_{3}(15 \mathrm{mg}, 0.03 \mathrm{mmol})$ and $(S, S)$ $2(13 \mathrm{mg}, 0.03 \mathrm{mmol})$ in dry DCM $(1.5 \mathrm{~mL})$ in $4 \mathrm{~mL}$ vial under the argon atmospehe were after $5 \mathrm{~min}$ of stirring at $20^{\circ} \mathrm{C}$ subsequently added cis-stilbene oxide 30 (59 mg, $0.3 \mathrm{mmol}$ ) and $p$-methoxybenzyl alcohol $(86 \mathrm{mg}, 0.6 \mathrm{mmol})$. After 12 hours of stirring at $20^{\circ} \mathrm{C}$, the corresponding spot of stilbene disappeared, so the volatiles were removed under reduced pressure. Column chromatography of the residue on silica gel $\left(5 / 1\right.$ hexanes/ $\left.\mathrm{Et}_{2} \mathrm{O}\right)$ furnished $83 \mathrm{mg}(82 \%, 98 \%$ ee $)$ of the title compound $\mathbf{3 1}$ as colorless crystals.

The recorded values were in agreement with the published data. ${ }^{[13]}$

\section{Acknowledgements}

E. B., Š. M., and M. K. would like to acknowledge financial support from the Czech Science Foundation (grant No. 1707707S), Grant Agency of Charles University (grant No. 243250362) and French embassy in Prague and M. D. from Ministry of Education of the Czech Republic (Project LO1304, Program "NPU-I"). E. B. and F. L. would like to thank Université de Montpellier, CNRS and French Ministry of Higher Education and Research for funding. Last but not least, M. K. would like to express his gratitude to the Institute for Molecular Science, Okazaki, Japan for funding of his visiting professorship. 


\section{References}

[1] A. P. Smith, C. L. Fraser, in Comprehensive Coordination Chemistry II (Ed. J. A. McCleverty, T. J. Meyer) Pergamon, Oxford, 2003, pp 1-23.

[2] a) N. C. Fletcher, J. Chem. Soc. Perkin Trans. 1 2002, 1831-1842; b) G. Chelucci, R. P. Thummel, Chem. Rev. 2002, 102, 3129-3170; c) S. E. Denmark, J. Fu, Chem. Rev. 2003, 103, 2763-2793; d) A. V. Malkov, P. Kočovský, Curr. Org. Chem. 2003, 7, 1737-1757; e) H.-L. Kwong, H.-L. Yeung, C.-T. Yeung, W.-S. Lee, C.-S. Lee, W.-L. Wong, Coord. Chem. Rev. 2007, 251, 2188-2222; f) C. A. Caputo, N. D. Jones, Dalton Trans. 2007, 46274640; g) E. Meggers Chem. Eur. J. 2010, 16, 752-758.

[3] F. Mongin, F. Trécourt, B. Gervais, O. Mongin, G. Quéguiner, J. Org. Chem. 2002, 67, 3272-3276.

[4] M. Tiecco, M. Tingoli, L. Testaferri, D. Chianelli, E. Wenkert, Tetrahedron 1986, 42, 1475-1485.

[5] F. Nissen, H. Detert, Eur. J. Org. Chem. 2011, 2845 2853.

[6] K. V. Rao, W. P. Cullen, Antibiot. Annu. 1959-1960, 950-953.

[7] J. Kobayashi, Y. Hirasawa, N. Yoshida, H. Morita, Tetrahedron Lett. 2000, 41, 9069-9073.

[8] C. Bolm, M. Zehnder, D. Bur, Angew. Chem. Int. Ed. Engl. 1990, 29, 205-207.

[9] S. Ishikawa, T. Hamada, K. Manabe, S. Kobayashi, Synthesis 2005, 2176-2182.

[10] S. Kobayashi, T. Endo, T. Yoshino, U. Schneider, M. Ueno, Chem. Asian J. 2013, 8, 2033-2045.

[11] E. Mai, C. Schneider, Chem. Eur. J. 2007, 13, 27292741.

[12] B. Plancq, T. Ollevier, Chem. Commun. 2012, 48, 38063808.

[13] C. Schneider, A. R. Sreekanth, E. Mai, Angew. Chem. Int. Ed. 2004, 43, 5691-5694.

[14] a) C. Ogawa, K. Kizu, H. Shimizu, M. Takeuchi, S. Kobayashi, Chem. Asian J. 2006, 1, 121-124; b) L. Zhu, T. Kitanosono, P. Xu, S. Kobayashi, Chem. Commun. 2015, 51, 11685-11688.

[15] T. Kitanosono, T. Ollevier, S. Kobayashi, Chem. Asian J. 2013, 8, 3051-3062.

[16] M. Kokubo, C. Ogawa, S. Kobayashi, Angew. Chem. Int. Ed. 2008, 47, 6909-6911.

[17] T. Kitanosono, M. Miyo, S. Kobayashi, ACS Sustainable Chem. Eng. 2016, 4, 6101-6106.

[18] M. Li, V. Carreras, A. Jalba, T. Ollevier, Org. Lett. 2018, 20, 995-998.

[19] M. Lafantaisie, A. Mirabaud, B. Plancq, T. Ollevier, ChemCatChem 2014, 6, 2244-2247.

[20] S. Kobayashi, T. Ogino, H. Shimizu, S. Ishikawa, T. Hamada, K. Manabe, Org. Lett. 2005, 7, 4729-4731.

[21] A. Tschöp, A. Marx, A. R. Sreekanth, C. Schneider, Eur. J. Org. Chem. 2007, 2318-2327.

[22] For a typical example, see: P. J. Walsh, M. C. Kozlowski, Fundamentals of Asymmetric Catalysis; University Science Books, 2009, Chpt. 4, p. 151-153.
[23] T. M. Suzuki, T. Kimura, Bull. Chem. Soc. Jpn. 1977, 50, 391-395.

[24] S. A. Chabolla, E. A. Dellamary, C. W. Machan, F. A. Tezcan, C. P. Kubiak, Inorg. Chim. Acta 2014, 422, 109113.

[25] For a typical example of influence of inductive effect, see: a) I. I. Grandberg, G. K. Faizova, A. N. Kost, Khim. Geterotsikl. Soedin. 1966, 2, 561-566; b) M. Taagepera, W. G. Henderson, R. T. C. Brownlee, J. L. Beauchamp, D. Holtz, R. W. Taft, J. Am. Chem. Soc. 1972, 94, 13691370.

[26] For an exemplary demonstration of steric and electronic effects in bipyridine ligands see: A. M. Al-Aljouni, A. Günyar, M-D Zhou, P. N. W. Baxter, F. E. Kühn Eur. J. Inorg. Chem. 2009, 1019-1026.

[27] K. Namba, J. Wang, S. Cui, Y. Kishi, Org. Lett. 2005, 7, $5421-5424$.

[28] E. Bednářová, E. Colacino, F. Lamaty, M. Kotora, $A d v$. Synth. Catal. 2016, 358, 1916-1923.

[29] CCDC 1834253 (8), 1834254 (2), and 1834255 (2-CuCl) contain supplementary crystallographic data for this paper. These data are available free of charge from The Cambridge Crystallographic Centre via www.ccdc. cam.ac.uk/data_request/cif.

[30] M. Kotora, T. Takahashi, in Palladium-Catalyzed Homocoupling of Organic Electrophiles or Organometals in Handbook of Organopalladium Chemistry for Organic Synthesis (Ed. E. Negishi) John Wiley and Sons, New York, 2002, pp 973-994.

[31] C. Barolo, J.-H. Yum, E. Artuso, N. Barbero, D. Di Censo, M. G. Lobello, S. Fantacci, F. De Angelis, M. Grätzel, M. K. Nazeeruddin, G. Viscardi, ChemSusChem 2013, 6, 2170-2180.

[32] M. P. A. Lyle, N. D. Draper, P. D. Wilson, Org. Biomol. Chem. 2006, 4, 877-885.

[33] Since the homocoupling did not affect the configuration of the center of chirality in $(S)-\mathbf{8}$, the configuration of $\mathbf{2}$ was assigned as $(S, S)$.

[34] W. Theilacker, H. Böhm, Angew. Chem. Int. Ed. 1967, $6,251$.

[35] No data regarding rotational barriers for 3,3'-disubstituted bipyridines have been reported so far, to the best of our knowledge.

[36] a) S. T. Howard, J. Am. Chem. Soc. 1996, 118, 1026910274; b) A. H. Göller, U.-W. Grummt, Chem. Phys. Lett. 2002, 354, 233-242; c) S. Zahn, W. Reckien, B. Kirchner, H. Staats, J. Matthey, A. Lützen, Chem. Eur. J. 2009, 15, 2572-2580.

[37] M. Kokubo, T. Naito, S. Kobayashi, Tetrahedron 2010, 66, 1111-1118.

[38] a) W.-S. Lee, C.-T. Yeung, K.-C. Sham, W.-T. Wong, H.L. Kwong, Polyhedron 2011, 30, 178-186; b) M. Kokubo, T. Naito, S. Kobayashi Chem. Lett. 2009, 38, $904-$ 905. 